\title{
MINI SEED 2 (MIS2) Encodes a Receptor-like Kinase that Controls Grain Size and Shape in Rice
}

Yan Chun ${ }^{1}$, Jingjing Fang ${ }^{1}$, Syed Adeel Zafar', Jiangyuan Shang ${ }^{1}$, Jinfeng Zhao ${ }^{1}$, Shoujiang Yuan ${ }^{2}$ and Xueyong $\mathrm{Li}^{i^{*}}$ (D)

\begin{abstract}
Background: Grain size is a key agronomic trait that is directly associated with grain yield in rice. Although several genes related to grain size in rice have been identified, our understanding of the mechanism of grain development is still limited.

Results: In this study, we reported the characterization of a novel seed size mutant mini seed 2 (mis2), in which the grain showed reduced length, width and thickness along with wrinkled surface. Microscopic analysis revealed that the spikelet epidermal cell size was reduced but the cell number was increased in the mis2 mutant, suggesting that MIS2 controls grain size by coordinately regulating epidermal cell size and cell number. Map-based cloning revealed that MIS2 encodes a receptor-like kinase CRINKLY4 (CR4) which showed the highest expression in developing panicles. The MIS2 protein is localized primarily on the plasma membrane along with the endosome. However, the Arg258GIn mutation located in extracellular domain in the mis2 mutant disturbed its subcellular localization. Additionally, three major haplotypes of MIS2 were identified in the japonica, indica and aus rice cultivars. The 18-bp InDel (insertion and deletion) in the 5'-UTR (untranslated region) caused different expression level of MIS2 in haplotypes.

Conclusions: We reported a key role of OsCR4 in controlling grain size and shape by coordinately regulating epidermal cell size and cell number. The Arg258 in the extracellular seven-repeat domain is essential for the correct subcellular behavior and function of the OsCR4 protein.
\end{abstract}

Keywords: Rice, Grain size and shape, Spikelets, Epidermal cells, Receptor-like kinase, CRINKLY4, OsCR4, MIS2

\section{Background}

Rice (Oryza sativa L.) is one of the most important grain crops providing food for over half of the world's population. To meet the demand of the increasing population, rice yield needs to increase up to $50 \%$ by 2030 (Ahmadi et al. 2014). Number of panicles per plant, number of grains per panicle, grain weight and size are key determinants of final grain yield in rice (Huang et al. 2013; Zafar et al. 2019). Grain size and weight usually have positive correlation with each other as grain weight normally depends on grain size (Tan et al. 2000). Thus, identification of genes controlling these key agronomic traits has

\footnotetext{
* Correspondence: lixueyong@caas.cn

${ }^{1}$ National Key Facility for Crop Gene Resources and Genetic Improvement, Institute of Crop Science, Chinese Academy of Agricultural Sciences, Beijing 100081, China

Full list of author information is available at the end of the article
}

been a promising goal of rice genetic improvement (Jiang et al. 2019a).

Several quantitative trait loci (QTL) have been reported that are linked with grain size and shape in rice, thus contributing toward breeding high yielding rice. However, only a few genes have been functionally characterized (Nan et al. 2018). Most of these genes regulate grain size and shape by affecting grain filling, cell number and cell size. GIF1 (GRAIN INCOMPLETE FILLING 1) encodes a cell-wall invertase, regulating rice grain filling and grain weight. Ectopic expression of the cultivated GIF1 gene with the CaMV35S or rice Waxy promoter resulted in smaller grains, whereas overexpression of GIF1 driven by its own promoter increased grain size (Wang et al. 2008). Many studies reveal that the number of cells in the hull of spikelet plays an important 
role in determining grain size (Xu et al. 2018a, 2018b). GW2, encoding a RING-type protein with E3 ubiquitin ligase activity, controls rice grain width and weight by regulating number of cells in spikelet (Song et al. 2007). Similarly, loss of function of GSN1 (GRAIN SIZE AND $N U M B E R$ 1), which encodes a mitogen-activated protein kinase phosphatase (OsMKP1), caused larger grains by increasing cell number due to enhanced cell division during spikelet development (Guo et al. 2018). XIAO, a putative LRR receptor-like kinase, is known to regulate organ size including leaves, panicles and grains via controlling number of cells while the cell size was constant (Jiang et al. 2012). Besides cell number, the cell size and shape are also important determinants of grain size. GL7 (GRAIN LENGTH ON CHROMOSOME 7)/GW7, a major QTL for rice grain length and width, encodes a protein homologous to Arabidopsis thaliana LONGIFOLIA protein and regulates spikelets longitudinal cell elongation (Wang et al. 2015a; Wang et al. 2015b). The longer and narrower spikelet hulls of NIL-GL7 plants were the result of an increase in cell length and a decrease in cell width of epidermal cells of the outer and inner glumes (Wang et al. 2015a). GLW7, encoding the plant-specific transcription factor OsSPL13, regulates grain length and thickness but does not regulate grain width. Loss of function of GLW7 causes reduced size of outer parenchyma cells, but the number of cells remains unchanged ( $\mathrm{Si}$ et al. 2015). In some instances, the grain size and shape are controlled by more than one factor at the same time. A putative serine carboxypeptidase GS5 positively controls grain size by regulating both grain width and grain filling. In the two near-isogenic lines (NILs) of GS5, the wider grains contain more number and large size of parenchyma cells (Li et al. 2011). GSE5 (GRAIN SIZE ON CHROMOSOME 5) is a plasma membrane-associated protein with IQ domains, which interacts with the rice calmodulin protein, OsCaM1-1. Loss of GSE5 function caused wide and heavy grains due to more and narrower spikelet epidermal cells in the mutant (Duan et al. 2017). These studies suggest that the rice grain shape and size are mainly determined by cell number and size.

Plant receptor-like kinases (RLKs) are among the largest protein super families with diverse extracellular domains that are linked with a conserved kinase domain via transmembrane part ( $\mathrm{Pu}$ et al. 2017). The extracellular domain functions as the major sensor module at the cell surface that regulates multiple biological pathways. The RLKs protein activation generally occurs in response to ligand binding of extracellular domain and subsequently, the downstream signaling is mediated by phosphorylation of the cytoplasmic kinase domain (Cock et al. 2002; Tichtinsky et al. 2003). The CRINKLY4 (CR4) family RLKs in angiosperms are known to regulate epidermal cell differentiation (Becraft et al. 1996; Watanabe et al. 2004; $\mathrm{Pu}$ et al. 2012). The first $\mathrm{cr} 4$ mutant was reported in maize which produced crinkled leaves and aleurone-defective kernels (Becraft et al. 1996). In Arabidopsis, loss of function of ACR4 led to the phenotypes including abnormal texture in integuments and seed coat, and reduced hydrophobicity on leaf surface (Gifford et al. 2003; Watanabe et al. 2004; Cao et al. 2005). The $\mathrm{cr} 4$ mutants also showed abnormalities in seed shape and differences in seed size (Gifford et al. 2003). In rice, knock-down of OsCR4 by RNA interference produced spikelets with separated palea and lemma, as a result of tumour-like cells in the outer epidermis and wart-like cells in the inner epidermis $\mathrm{Pu}$ et al. 2012). However, the function of OsCR4 in the regulation of rice grain size is still not clear.

In the present study, we isolated a small seed mutant "mini seed 2 (mis2)" in rice that displayed smaller grains with irregular shape. The mis 2 mutant spikelet had reduced cell size but increased cell number, which suggests MIS2 regulates grain size through coordinate regulation of cell size and cell number. The candidate gene MIS2 encodes the receptor-like kinase OsCR4 and the mutation in the mis2 caused the disturbed subcellular behavior of MIS2 protein. Moreover, we identified three major haplotypes from over 500 core rice germplasm. Our study provides a new perspective of OsCR4 function in regulating grain size and shape in rice.

\section{Methods}

\section{Plant Materials and Growth Conditions}

The mis2 mutant was isolated from ethyl methane sulfonate (EMS)-treated seeds of the elite japonica variety, XuDao3 (XD3). For genetic analysis and map-based cloning, the mis 2 mutant was crossed with the indica variety Dular. All rice plants were cultivated in paddy fields in Beijing, Shandong and Hainan provinces under natural growth conditions.

\section{Phenotypic Analysis Using Simple and Electron Microscopy}

Photographs of plants and panicles were taken using a Digital camera (Nikon). Photographs of mature seeds (with and without hulls) were taken using stereomicroscope (Olympus). For cross section analysis, the young spikelets of WT and the mutant were fixed in FAA (50\% ethanol, 5\% glacial acetic acid, and 5\% formaldehyde) overnight at $4{ }^{\circ} \mathrm{C}$, then dehydrated in a graded ethanol series as described previously (Zafar et al. 2019). After fixing with xylene, the samples were embedded in paraplast (Sigma). The embedded samples were sliced into $8-10 \mu \mathrm{m}$ thick sections with a rotary microtome (Leica). Sections were dewaxed in xylene, hydrated through a 
graded ethanol series, stained with $1 \%$ fast green and observed under a light microscope (Olympus).

For scanning electron microscopy (SEM), the spikelets at maturity were fixed in 3.5\% glutaraldehyde solution and then dehydrated through an ethanol series. After dehydration process, the samples were dried by criticalpoint drying method and sputter-coated with aurum, and then observed under the scanning electron microscope (Hitachi). Cell length and cell width of spikelets were measured using Image J software.

For transmission electron microscopy (TEM), the young spikelets before heading stage were fixed by $2.5 \%$ glutaraldehyde solution (PH 7.2) and vacuum-infiltrated. The samples were washed three times with $0.2 \mathrm{~mol} / \mathrm{L}$ sodium cacodylate buffer for $30 \mathrm{~min}$, fixed in $10 \%$ osmic acid for $1 \mathrm{~h}$, washed three times with deionized water for $45 \mathrm{~min}$, dehydrated with ethanol and treated with acetone. Samples were then embedded in epoxy resins and polymerized at $70^{\circ} \mathrm{C}$ and then cut into about $500-800 \AA$ thin sections and stained by the mixture of uranyl acetate dihydrate and led citrate. The sections were washed with deionized water and visualized using HITACHI Transmission Electron Microscope (HT7700).

\section{Map-Based Cloning of MIS2}

$\mathrm{F}_{2}$ mapping population was generated by crossing mis 2 with indica variety Dular. Primary mapping was conducted with InDel markers by $60 \mathrm{~F}_{2}$ mutant individuals. To fine-map the MIS2 locus, new molecular markers were developed. MIS2 was mapped to a $213-\mathrm{kb}$ region on chromosome 3 , and genes from this region were amplified and sequenced from both mis2 and the WT. The primer sequences for the InDel markers are showed in Additional file 1: Table 1.

\section{Vector Construction and Plant Transformation}

To make the genomic DNA complementation construct, the 5997-bp genomic DNA fragment of MIS2 including 2867-bp upstream of start codon and 425-bp downstream of stop codon was amplified from the WT and cloned into EcoRI and PmlI sites of the plant binary vector $p C A M B I A 1305.1$. For the promoter-GUS vector, a 2870-bp fragment upstream of the MIS2 start codon was amplified from WT and cloned into the $p C A M$ BIA1305.1 vector to generate the plasmid ProMIS2:GUS. The constructs after sequencing were transformed into rice calli by Agrobacterium tumefaciens mediated transformation. In-Fusion HD Cloning Kit (Clontech) was used in this study to produce various DNA constructs. The PCR primers are given in Additional file 1: Table 1.

\section{RNA Extraction and Quantitative Real-Time PCR}

Total RNA was extracted from various plant organs of the WT using RNAprep Pure Plant Kit (TIANGEN) and was reverse transcribed using HiScript II Q RT SuperMix (Vazyme). Quantitative real-time PCR analysis was performed on an Applied Biosystems 7500 Real-Time PCR System with $2 \times$ ChamQ SYBR Color qPCR Master Mix (Vazyme) and the data were calculated using the $2^{-\Delta \Delta C t}$ quantification method. The rice Ubiquitin gene was used as an internal control to normalize gene expression. All primers used are listed in Additional file 1: Table S1.

\section{GUS Staining}

The histochemical GUS activities were detected as described previously (Jefferson et al. 1987). The samples were vacuum-infiltrated for $30 \mathrm{~min}$ in GUS staining buffer. After overnight incubation in dark at $37^{\circ} \mathrm{C}$, the samples were cleared using ethanol to remove chlorophyll and then photographed using stereomicroscope (Olympus).

\section{Subcellular Localization of MIS2}

To determine the subcellular localization of normal and mutated versions of MIS2, the coding region of MIS2 and $M I S 2^{m u}$ were amplified from WT and the mis2 mutant cDNA, and fused with GFP at C-terminus, respectively. The coding region of Ara6 was amplified from Arabidopsis Col-0 and fused with mCherry at C-terminus. MIS2 and $M I S 2^{m u}$ were driven by rice actin 1 promoter, and Ara6 was driven by CaMV35S promoter. The constructs were introduced into Agrobacterium tumefaciens strain GV3101 and infiltrated into the Nicotiana benthamiana leaves. The GFP and mCherry fluorescence in leaf epidermal cells was detected with the LSM 510 META confocal lasers scanning microscope (Zeiss). The sequences of the PCR primers used for vector construction are given in Additional file 1: Table 1.

\section{Bioinformatics Analysis}

The three-dimensional modeling of the MIS2 extracellular crinkly repeats was undertaken based on the $\mathrm{x}$-ray structures of photoreceptor AtUVR8 mutant W285F and lightinduced structural changes at $120 \mathrm{~K}$ (Zeng et al. 2015). The protein shares $18.75 \%$ pairwise identity with the query sequence (Arnold et al. 2006; Benkert et al. 2011; Biasini et al. 2014). The structure was assigned by the standard settings within PyMol 2.2.0 (https://pymol.org). Alignment was conducted by Clustal W and phylogenetic analysis was performed using MEGA X (Kumar et al. 2018). GENEDOC was used to show the consensus and shading.

\section{Haplotype Analysis}

The genotype data of the 524 accessions was obtained via the $3 \mathrm{~K}$ Rice Genomes Project from NCBI (https:// www.ncbi.nlm.nih.gov/sra/?term=PRJEB6180) (Wang et al. 2018). The alleles of low frequency in the 524 panels were considered missing, and the heterozygous alleles were also eliminated. 


\section{Results}

\section{Phenotypic Characterization of the mis2 Mutant}

The mis2 mutant was isolated from the $\mathrm{M}_{2}$ population of $j a$ ponica cv. XuDao 3 (XD3) mutagenized by ethyl methane sulphonate (EMS). Compared with the wild type (WT), the mis2 mutant has small grains with irregular shape and open glumes (Fig. 1a). The grain size including grain length, width, thickness and 1000-grain weight was significantly reduced in the mis2 mutant as compared to WT (Fig. 1b-e). In addition to the grain size and shape, several other agronomic traits were also affected in the mis 2 mutant. The mis 2 mutant was shorter in height and produced more tillers per plant (Additional file 1: Figure S1a, d, e). In addition, the seed setting rate was also decreased in the mis 2 compared with the WT, while the spikelet number per panicle was increased (Additional file 1: Figure S1 g, h). However, the panicle length was not changed significantly between the WT and mis2 mutant (Additional file 1: Figure S1b, c, f). These observations indicated that MIS2 has significant contribution in determining the various seed morphology related characters and controls seed size in rice. mis2 Affects Grain Size by Coordinately Regulating the Epidermal Cell Size and Cell Number

To reveal the cellular basis of smaller grain size in the mis 2 mutant, both outer and inner surfaces of mature lemmas and paleas of the WT and the mis2 mutant were observed by scanning electron microscopy (SEM). In the WT, regular and linear arrangement of epidermal silicified cells was observed in the outer epidermal surface of the lemma and palea (Fig. 2a, c). In contrast, the epidermal cells in the mis 2 mutant were wrinkled with variable shape and size (Fig. 2b, d). More detailed observations indicated that the length and width of the epidermal cells was significantly reduced in the mis 2 mutant as compared with WT (Fig. 2e, f). However, the epidermal cell number of the lemma and palea was increased to different extents in both grain-length and grain-width directions (Fig. 2g). Regarding the inner surface, the epidermis of the lemma and palea of the WT was smooth, whereas in the mis 2 mutant, it was uneven and produced wart-like structures (Fig. 2h-k). Taken together, these observations demonstrated that MIS2 is a positive

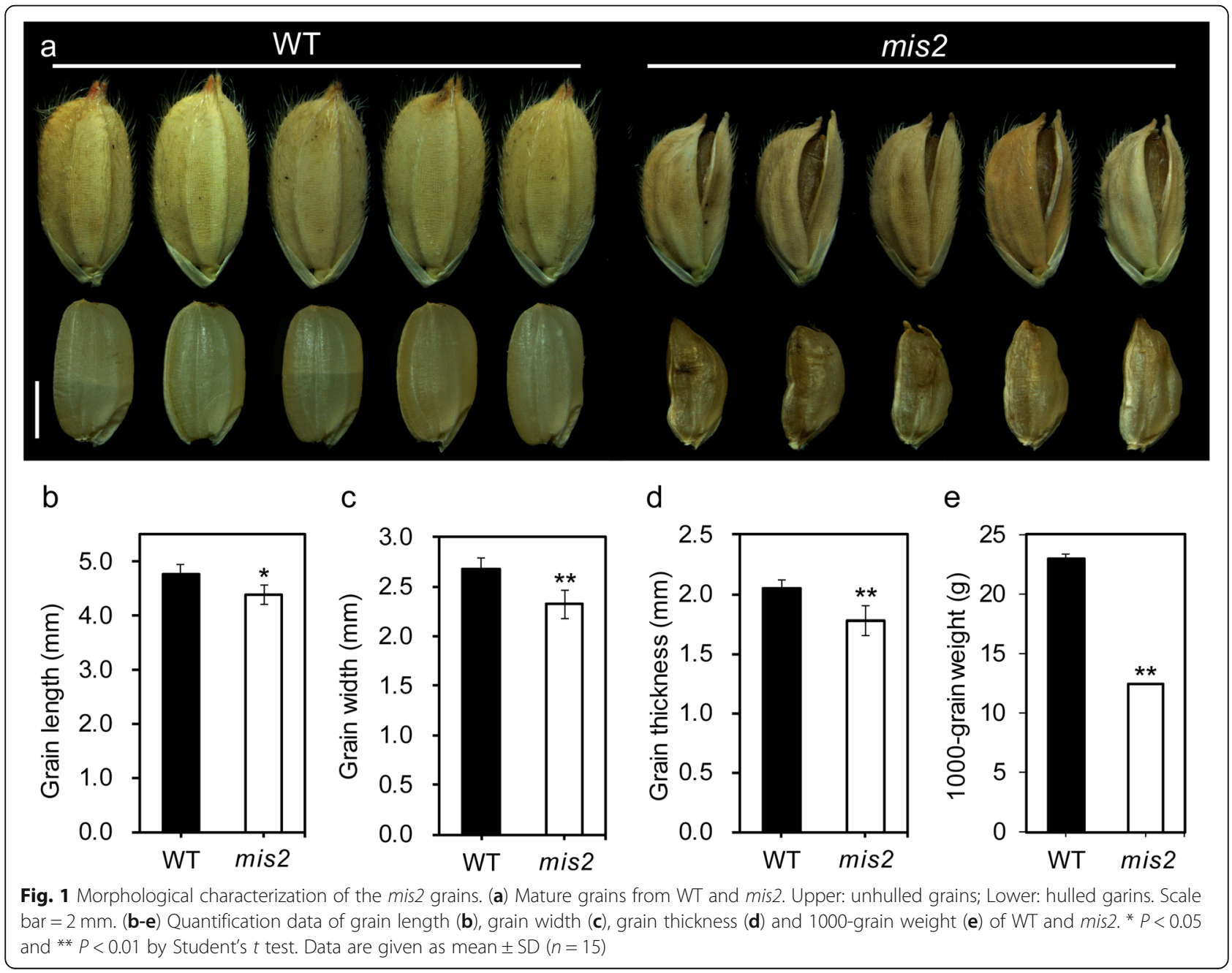



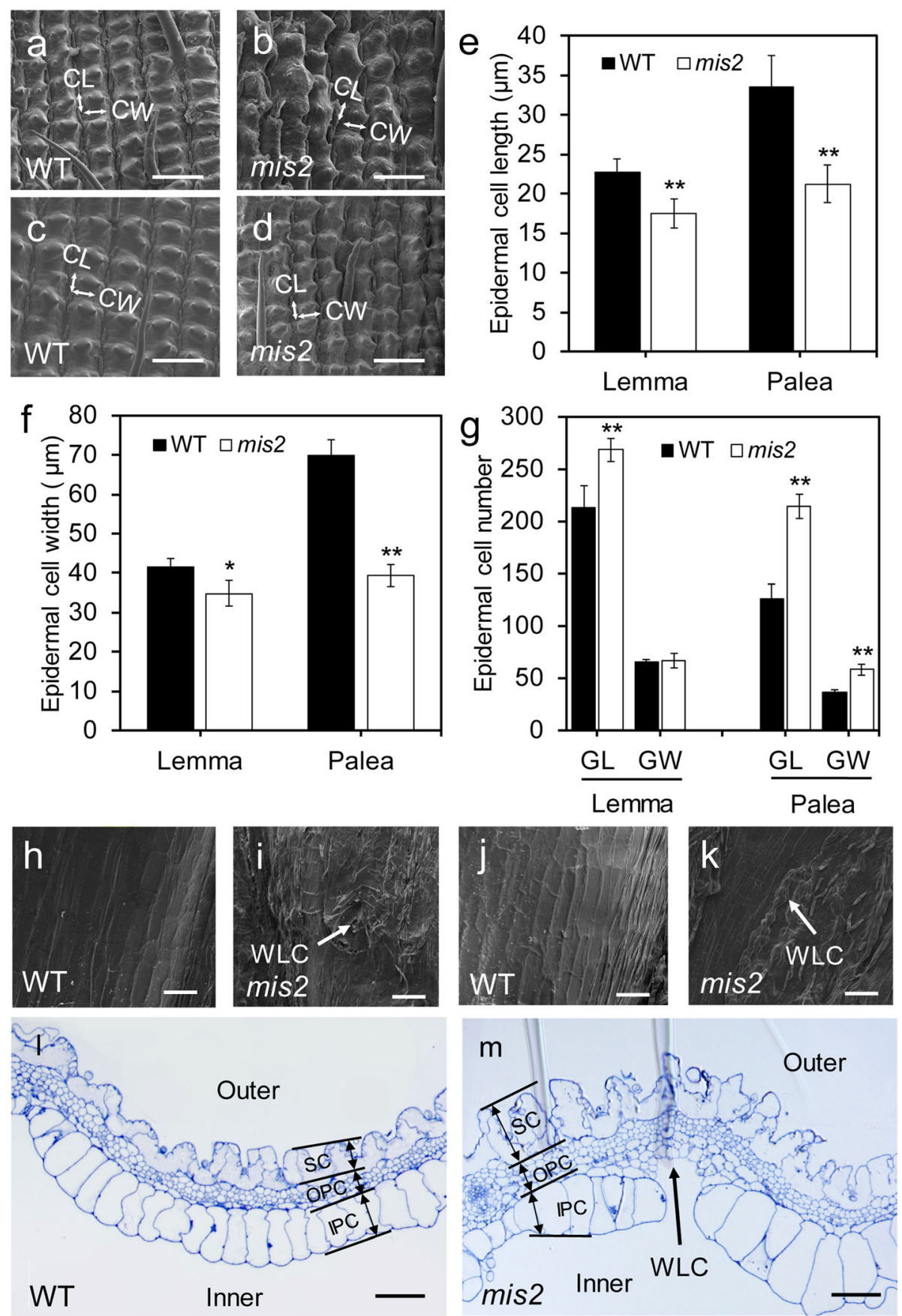

Fig. 2 Comparison of the spikelet epidermal cells between WT and mis2. (a-d) Scanning electron micrographs (SEM) for the outer surfaces of lemma $(\mathbf{a}, \mathbf{b})$ and palea $(\mathbf{c}, \mathbf{d})$ of WT $(\mathbf{a}, \mathbf{c})$ and mis2 $(\mathbf{b}, \mathbf{d})$. CL and CW indicate epidermal cell length and cell width orientation, respectively. Bars $=100 \mu \mathrm{m}$. (e, f $)$ The average length and width of the epidermal cells. $(n=10)$. (g) Comparisons of the calculated epidermal cell number of the lemma and palea in the grain-length (GL) and grain-width (GW) direction, respectively $(n=10)$. (h-k) SEM for the inner surfaces of lemma (h/ i) and palea (j, k) of WT and mis2. Bars $=100 \mu \mathrm{m}$. (I, m) Cross sections of WT and mis2 spikelet hull. Bar $=50 \mu \mathrm{m}$. WLC, wart-like cells; SC, silicified cells; OPC, outer parenchyma cells; IPC, inner parenchyma cells. ${ }^{*} P<0.05$ and ${ }^{* *} P<0.01$ by Student's $t$ test. Data are given as mean \pm SD $(n=20)$

regulator of grain size and shape and coordinately regulates spikelet epidermal cell size and number. Cross section observations of the lemma and palea further validated our SEM results. We observed a regular pattern of three cell layers including silicified cells (SC), outer parenchyma cells (OPC) and inner parenchyma cells (IPC) in the WT (Fig. 2l). However, the epidermal silicified cells in the mis 2 mutant were unclear and 
disordered (Fig. 2m). The cells of the OPC layer were also irregular and more in number in the mis 2 mutant as compared with WT (Fig. 2l, m). We also observed remarkable difference in the cells of the IPC layer among WT and mis2. The cells of IPC layer were uniform in shape and size in WT while those of mis 2 were of irregular shape and variable size (Fig. 2l, m). The IPC layer was also discontinuous in some locations in the mis2 mutant.

We also observed the grain surface of the WT and mis2 mutant using SEM. This observation displayed smooth epidermis layer in the WT while rough and wrinkled epidermal layer in the mis2 mutant (Fig. 3a, b). A closer observation indicated that grain epidermis was full of cracks in the mis 2 as compared with WT (Fig. 3c, d). These findings suggest that MIS2 also plays role in determining grain shape and surface in rice.

\section{The mis2 Mutant Has Defective Interlocking Structures and Epidermal Cell Wall}

The lemma and palea of the WT spikelets were interlocked tightly, whereas the mis 2 mutant displayed openhull spikelets (Fig. 1a). To analyze this abnormal phenotype, the interlocking structures were investigated by transmission electron microscopy (TEM). In the WT, two hook-like structures were tightly interlocked but the interlocking structure was defective in the mis 2 mutant (Fig. 4a, b). Although, there is no obvious difference in interlocking cells of lemma, however, the cells at the joint in the palea were fewer than those in the WT and showed amorphous shape, leading to the disappearance of hook-like structure (Fig. 4b).
In the WT, the epidermal cells at the interlocking position were covered with an even cell wall, and the cell wall was fused with a clear cuticle layer (Fig. 4c, e). In the mis2 mutant, however, the cell wall of those cells was curved and fused with a thin cuticle layer which was either uneven or not as clear as that in the wild type (Fig. 4d, f). These observations suggest that the mis2 mutant had defective development of cell wall and cuticle layer of interlocking cells in the lemma and palea.

\section{MIS2 Encodes the Receptor-like Kinase OsCR4}

To know the causal gene underlying the mis 2 phenotype, the mis 2 mutant was crossed with the WT cv. XD3. All the $F_{1}$ plants had normal grains as WT. The $F_{2}$ population was segregated in a 3:1 ratio generating 276 WT-like plants having normal grains and 85 mis2-like plants having small and wrinkled grains $\left(x^{2}=0.407, \chi_{0.05,1}^{2}=3.84\right)$. This indicated that the mis 2 mutant phenotype was regulated by a single recessive gene. Using $60 \mathrm{~F}_{2}$ mutant plants from a cross between the mis 2 mutant and the indica variety Dular, the MIS2 gene was primarily mapped on chromosome 3 between two insertion-deletion (InDel) markers M2 and M3 (Fig. 5a). For fine mapping, 14 InDel markers were developed and the MIS2 locus was narrowed to a $213-\mathrm{kb}$ region by a $\mathrm{F}_{2}$ population consisting of 218 mutant plants. This region contained 21 open reading frames (ORFs) based on MSU Rice Genome Annotation Project (http://rice.plantbiology.msu.edu/) (Fig. 5b, c), including 13 functional proteins, three expressed proteins and five retrotransposons.

To determine the candidate gene, 16 genes encoding functional or expressed protein were amplified and sequenced from both the WT and mis2 mutant genomic
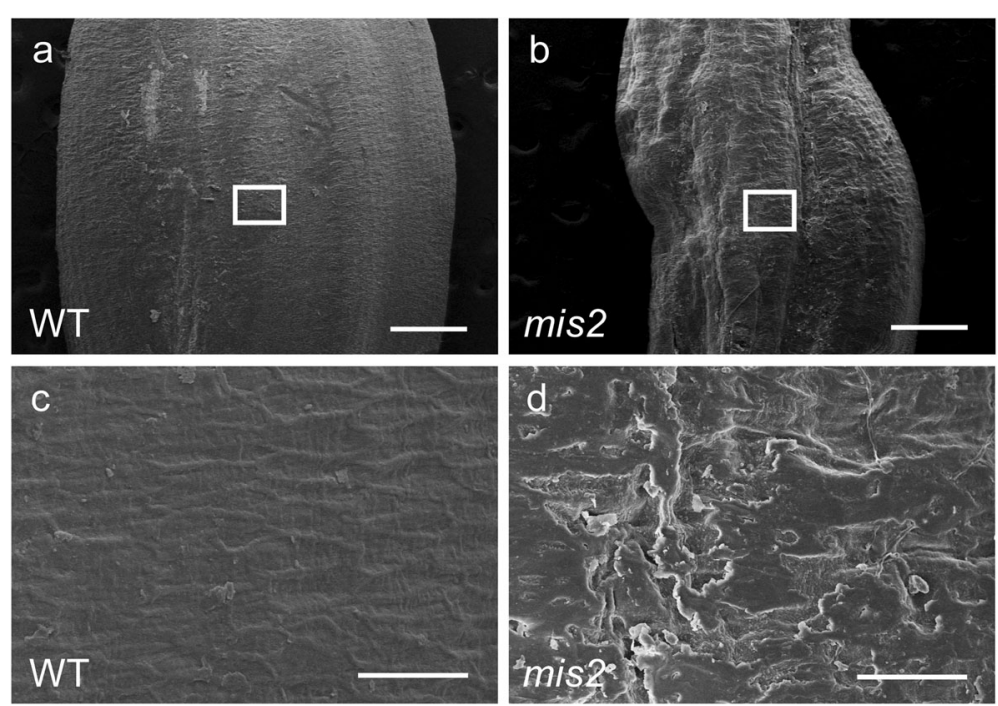

Fig. 3 Morphological comparison of seed surface between WT and mis2. (a, b) SEM for the surface of WT and mis2 seed. Bar = $0.5 \mathrm{~mm}$. (c, d) Magnified views of the boxed region in $(\mathbf{a}, \mathbf{b})$, respectively. Bar $=50 \mu \mathrm{m}$ 

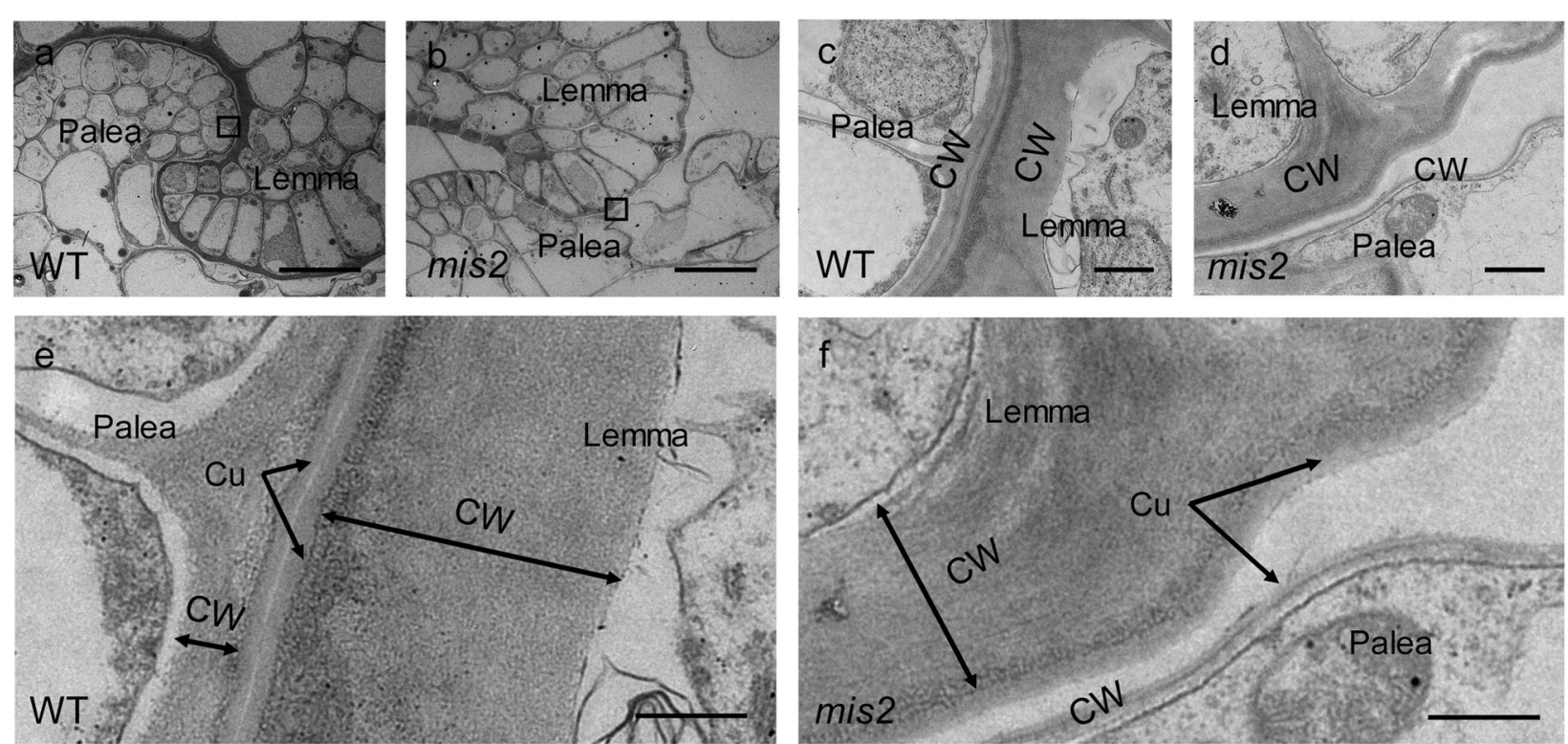

Fig. 4 Comparison of the interlocking cells, cell wall and cuticle layer between WT and mis2. (a, b) Transmission electron micrographs (TEM) for the interlocking cells of the palea and lemma in the WT and mis2. Bar $=10 \mu \mathrm{m}$. (c, d) Magnified views of the boxed region in (a, b), respectively. Bar $=5 \mu \mathrm{m}$. (e, f) Cuticle and cell wall of interlocking cells in the WT and mis2. Bar $=1 \mu \mathrm{m}$. Cu, cuticle; CW, cell wall

DNA. A single-nucleotide substitution in the mis2 mutant was detected in the ORF3 (LOC_OsO3g43670) which contains 3 exons, and no mutation was found in other 15 genes. According to the annotation on MSU Rice Genome Annotation Project, ORF3 encodes the putative receptorlike kinase CRINKLY4 (OsCR4) which contains a sevenrepeat structure and Ser (serine)/ Thr (threonine) kinase domain. The mutation from $\mathrm{G}$ to $\mathrm{A}$ was detected on the third exon, causing the replacement of 258th amino acid arginine (R) with glutamine (Q) (Fig. 5d). The R258Q substitution in the mis2 mutant occurred on the sixth repeat of OsCR4 (Additional file 1: Figure S2). To verify whether ORF3 was responsible for the mis2 mutant phenotype, the complete genomic DNA of ORF3 including its own promoter (around $1.8 \mathrm{kp}$ upstream of ATG) was transformed into the mis2 mutant. Seven transgenic lines carrying the ORF3 fragment were obtained and all of them fully complemented the mutant phenotype having large grains with smooth surface and closed-hulls (Fig. 5e). This data confirmed that $O R F 3$, which is referred to as MIS2 hereafter, was the candidate gene for the mis 2 mutant phenotype.

To know the evolutionary relationship of MIS2 with other CR4 family proteins, a phylogenetic analysis was conducted using MEGA-X version 10.0.1. The CR4 family and their related proteins in Arabidopsis, rice and maize fell into two major clusters. The first cluster contained two subclades, one having only Arabidopsis CRR proteins and other subclade having only CR4 proteins from Arabidopsis, rice and maize (Fig. S3). The other cluster contained only CRR proteins from different species. Notably, no ortholog of AtCRR1 and AtCRR2 in rice and maize was found (Additional file 1: Figure S3).

\section{Expression Pattern of MIS2}

To examine the spatio-temporal expression pattern of MIS2, quantitative real-time PCR (qRT-PCR) and histochemical promoter-GUS staining approaches were used. The qRT-PCR analysis indicated that the expression level of MIS2 was relatively higher in panicle tissues than other organs (Fig. 6a). Notably, the expression was gradually increased in developing panicles with the highest expression in panicle at $15-\mathrm{cm}$ length stage which is corresponding to the anthesis stage. After that, it started to decrease in mature panicle (Fig. 6a).

The results of promoter-GUS assay were more or less consistent with qRT-PCR. Histochemical staining of transgenic plants indicated low expression in leaf and roots as compared with stem (Fig. 6b-e) and highest expression in developing panicles (lemma and palea) (Fig. 6f). These results also suggested that MIS2 functions mainly during the spikelets development.

\section{mis2 Disrupted the Distribution and Recycle of OsCR4}

OsCR4 encoded by the MIS2 gene is one of the typical receptor-like kinases of the TNFR (Tumor Necrosis Factor Receptor-like) subfamily. OsCR4 contains a sevenrepeat extracellular domain (Fig. 7a), a tumor necrosis factor receptor domain, a single transmembrane helix and an intracellular Ser/Thr kinase domain (Additional file 1: Figure S2). It is known that ACR4, the ortholog of OsCR4 in Arabidopsis, is localized on plasma membrane 


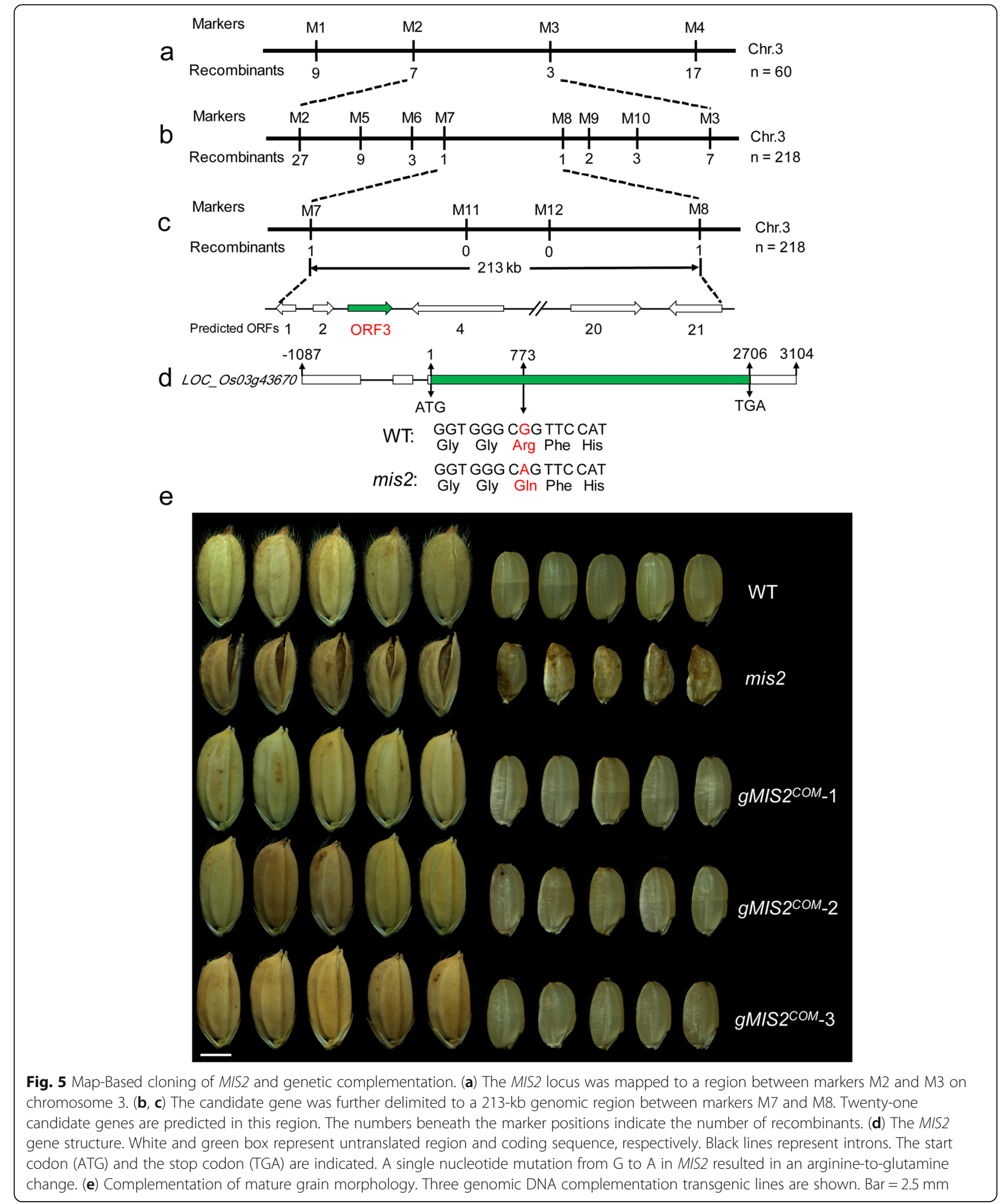

and endosomes (Giffhord et al. 2005; Tian, et al. 2007). Meanwhile, ACR4 protein can be internalized and turned over through two distinct endosomes in Arabidopsis root cells, representing a population of internalized vesicles and protein export bodies. It is also known that the extracellular seven-repeat domain is required for the ACR4 function, internalization and turnover (Giffhord et al. 2005; Qin et al. 2019). 

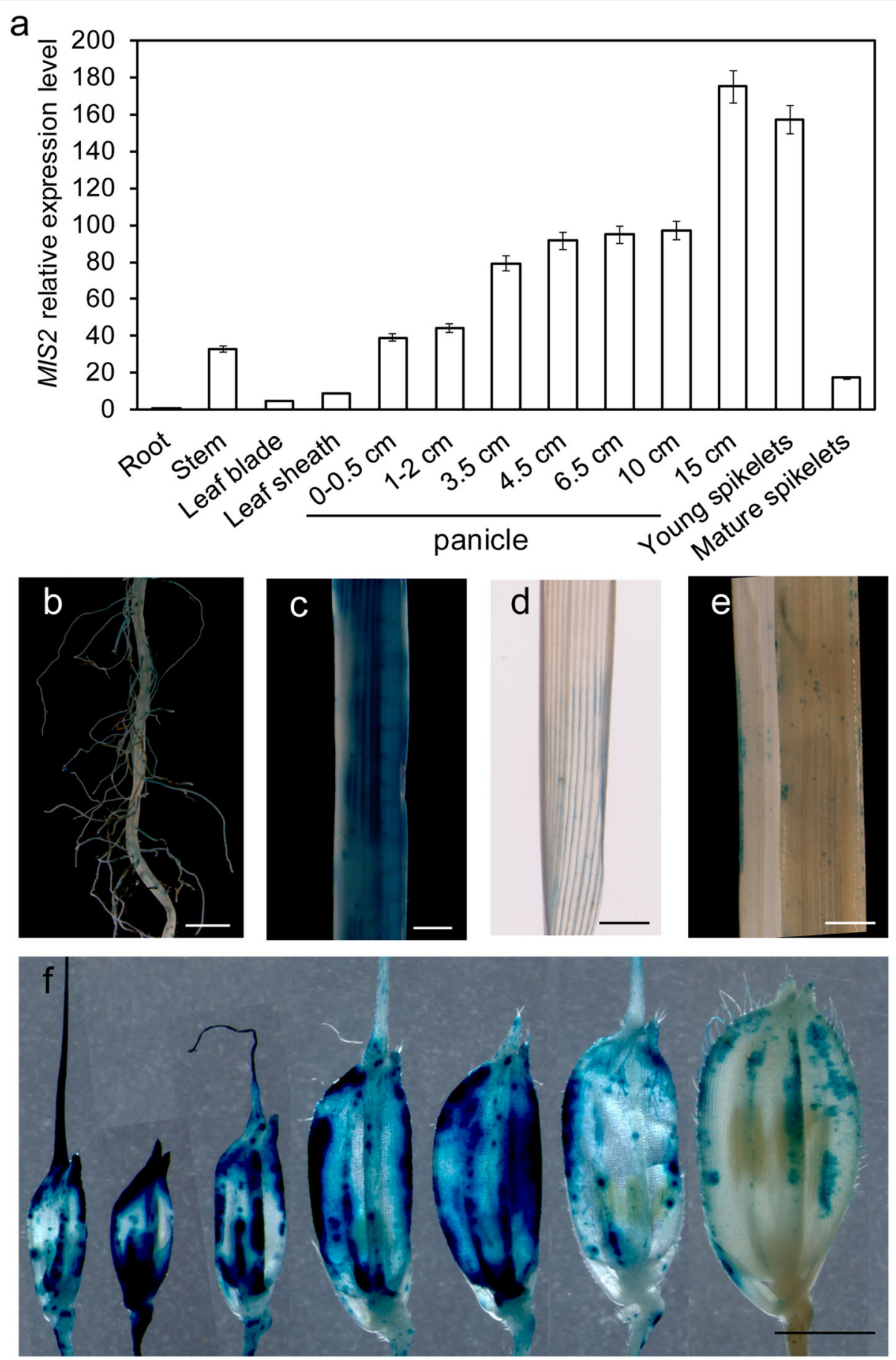

Fig. 6 Expression pattern of MIS2. (a) Quantitative RT-PCR analysis showing the relative expression level of MIS2 in root, stem, leaf blade, leaf sheath, young panicle at various length stage, young spikelets and mature spikelets. The rice ubiquitin gene was used as an internal control. Values are given as mean \pm SD $(n=3)$. (b-f) Expression pattern of GUS gene driven by the MIS2 promoter in root (b), stem (c), leaf blade (d), leaf sheath (e) and spikelets at different stages (f). Bar $=2 \mathrm{~mm}$

In the mis2 mutant, the R258Q substitution occurred on the sixth repeat of the extracellular domain (Fig.7a and Additional file 1: Figure S2). To see whether this mutation affected the subcellular behavior of MIS2 protein, the coding sequence (CDS) of MIS2 from WT and the mis2 mutant were fused with GFP and co-expressed with ARA6 (At3g54840) which was fused with mCherry, respectively, in tobacco (Nicotiana benthamiana). ARA6 is a plant-unique Rab5 GTPase in Arabidopsis which mediates trafficking from endosomes to the plasma 


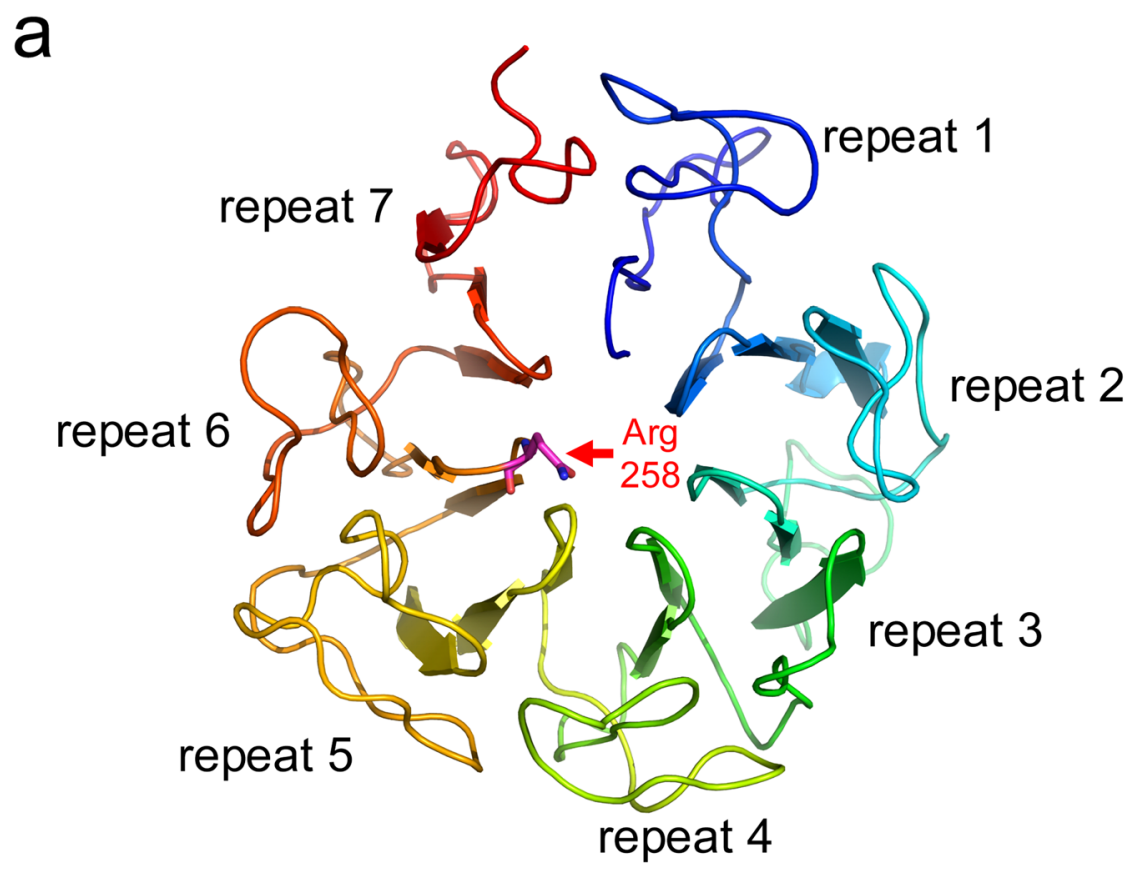

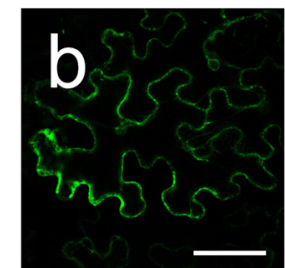

MIS2-GFP

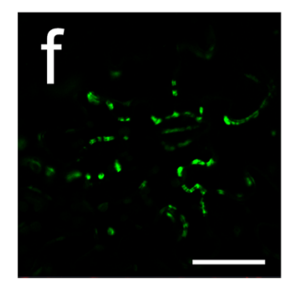

MIS2mu_GFP

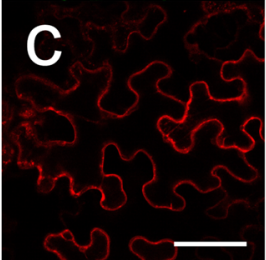

ARA6-mCherry

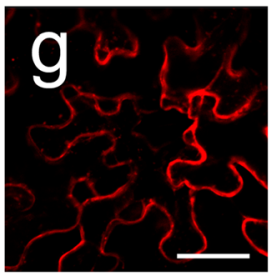

ARA6-mCherry

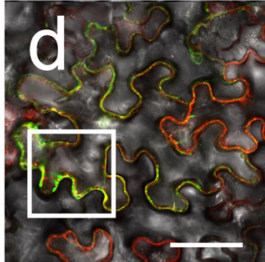

merge

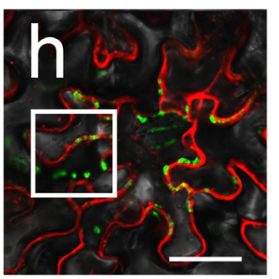

merge

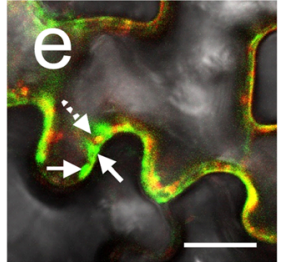

merge

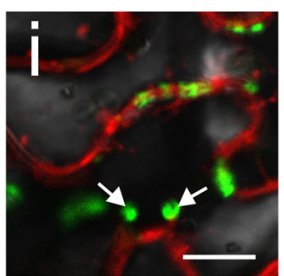

merge

Fig. 7 Subcellular behavior of MIS and MIS2 ${ }^{\text {mu }}$ protein. (a) Three-dimensional model of the MIS2 extracellular repeat domain using PyMol. Seven repeats are labeled and Arg 258, which is mutated to Gln in mis2, is shown as a stick and colored purple. (b-e) Co-expression of MIS2 and ARA6 in tobacco leaf. The florescence of MIS2::GFP (b) and ARA6::mCherry (c) were detected and merged on the plasma membrane (d). The merged image (e) is a magnification view of the boxed region in (d). Line arrows indicate GFP-only vesicles, and dot arrows indicate co-localizations. Bar $=20 \mu \mathrm{m}(\mathbf{b}-\mathbf{d}), \operatorname{Bar}=10 \mu \mathrm{m}(\mathbf{e}) .(\mathbf{f}-\mathbf{i})$ Co-expression of MIS2 ${ }^{\mathrm{mu}}$ and ARA6 in tobacco leaf epidermal cells. ARA6:"mCherry is localized on plasma membrane (g). MIS2 ${ }^{\text {mu. }: G F P ~ l o c a l i z a t i o n ~ i s ~ c o n s i d e r a b l y ~ c h a n g e d ~}(\mathbf{f}, \mathbf{h})$. Magnification view shows GFP-labeled and mCherry-labeled compartments in cytoplasm and no colocalization is observed (I). Line arrows indicate GFP-only vesicles, respectively. Bar $=20 \mu \mathrm{m}$ (f-h), Bar $=10 \mu \mathrm{m}$ (i)

membrane but counteracts endocytic trafficking from the endosomes to the vacuoles (Ebine et al. 2011; Tsutsui et al. 2015). ARA6 is localized to the plasma membrane and small punctate structures in the early step of the endocytic pathway (Ueda et al. 2001; Ebine et al. 2011). The green signals of MIS2::GFP were observed in the plasma membrane and could merge with ARA6:: mCherry (Fig. 7b-d). Meanwhile, some cells have shown the presence of two distinct populations of GFP- containing bodies, one merged with mCherry (Fig. 7e, dot arrow) and the other only with GFP (Fig. 7e, line arrow), representing protein export bodies and internalized vesicles, respectively. This indicated that the subcellular behavior of MIS2 protein is similar to ACR4, which could be internalized and rapidly turned over. In contrast, the mutated version of MIS2 (MIS2 ${ }^{\mathrm{mu}}:$ GFP) was localized in the cytoplasm near the plasma membrane but could not merge with ARA6:mCherry (Fig. 7f-h). A 
few large GFP-containing bodies were observed in cytoplasm representing the internalized vesicles (Fig. 7i, line arrow). However, none of these vesicles merged withARA6:mCherry, suggesting that the internalized protein can not be exported and recycled to the membrane. Thus, we concluded that the R258Q substitution in the extracellular domain disrupted the distribution and turnover of MIS2 protein in the mis2 mutant, leading to the insufficient replenishment of OsCR4 onto the plasma membrane.

\section{mis2 Affected the Expression of Genes Related to Epidermal Differentiation, Grain Size and BRs}

The expression of ACR4 in Arabidopsis is regulated by HD-ZIP class IV transcription factors Arabidopsis thaliana MEIRISTEM LAYER 1 (ATML1) and PROTODERMAL FACTOR 2 (PDF2) in a negative feedback model (San-Bento, et al. 2014). ATML1 and PDF2 positively or negatively regulate $A C R 4$ expression via the $\mathrm{L} 1$ box (Tanaka, et al. 2002; Abe, et al. 2003; San-Bento, et al. 2014), and ACR4 positively regulates epidermal cell differentiation upstream of ATML1 (Tanaka et al. 2007). The ortholog of ATML1 and PDF2 in rice is Rice outermost cell-specific gene 5 (ROC5) and thus the relative expression level of $R O C 5$ and other paralogous genes in young panicle $(\sim 1 \mathrm{~cm})$ was examined in the WT and mis 2 mutant (Fig. 8a). ROC5 has essential roles in the formation and development of epidermal bulliform cells in rice, and the ROC5 T-DNA insertion knockout mutant had significantly increased bulliform cell number and size, producing the abaxially rolled leaf (Zou et al., 2011). However, the role of $R O C 5$ in regulating rice grain size and the spikelet epidermal cells development is not known.

To investigate the possible regulatory relationship between MIS2 and other previously identified genes that are involved in rice grain size and shape, the transcript

\section{a}

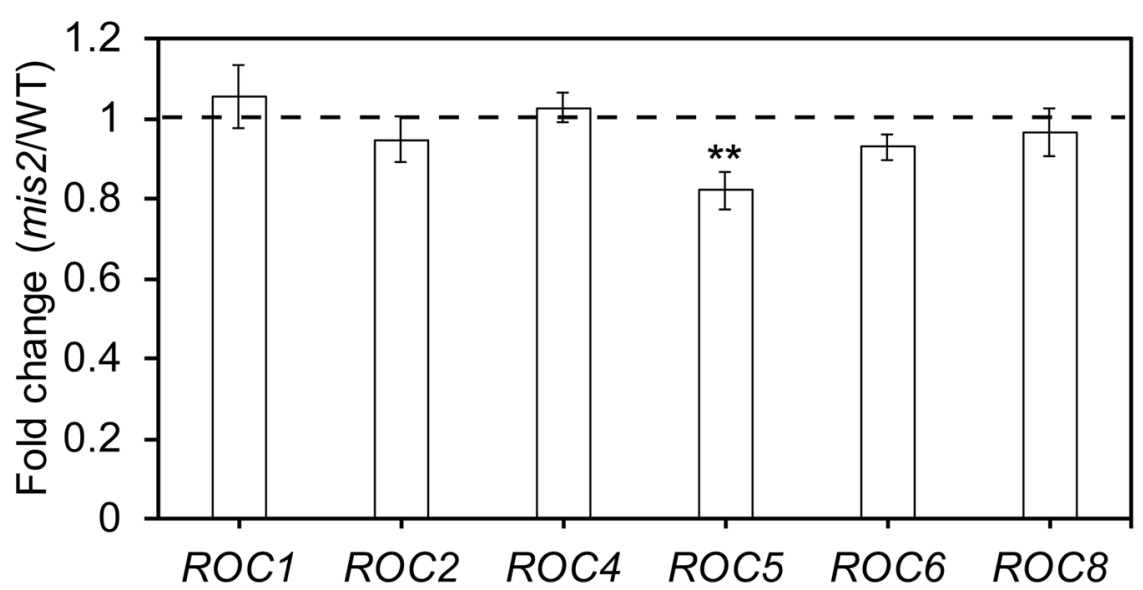

b

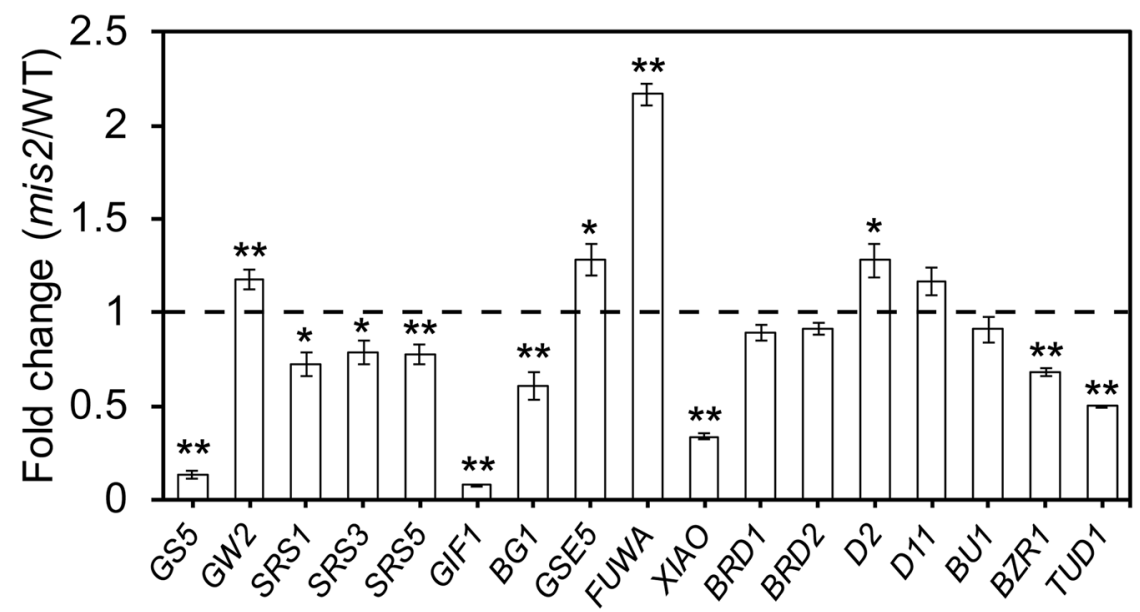

Fig. 8 Quantitative RT-PCR analysis of epidermal cell development, grain size and BRs related genes. (a) Relative expression fold change of ROC5 and related genes in WT and mis2. (b) Relative expression fold change of genes related to grain size and BRs in WT and mis2. Young inflorescence of $\sim 1 \mathrm{~cm}$ was used for analysis. Rice ubiquitin gene was used as an internal control. ${ }^{*} P<0.01$ and ${ }^{*} P<0.05$ by Student's $t$ test. Values are given as mean \pm SD $(n=3)$ 
levels of some grain size and shape related genes were detected (Song et al. 2007; Abe et al. 2010; Kitagawa et al. 2010; Li et al. 2010; Li et al. 2011; Jiang et al. 2012; Segami et al. 2012; Chen et al. 2015; Liu et al. 2015; Duan et al. 2017;). The expression level of GIF1 which positively regulates grain filling was significantly decreased (Fig. 8b). SRS3 and SRS5 which positively control the spikelet epidermal cell size or shape were significantly down regulated in the mis 2 mutant (Fig. $8 \mathrm{~b})$. The genes which positively regulate the spikelet epidermal cell number including GS5 and XIAO were also down regulated, whereas the negative regulators $G W 2$ and FUWA were up regulated (Fig. 8b). Additionally, the expression levels of genes which control both cell size and cell number were significantly changed such as GSE5, SRS1 and BG1 (Fig. 8b). Brassinosteroids (BRs) are a class of vital phytohormones and their roles in the regulation of seed size have been well reported (Mori et al. 2002; Tanaka et al. 2009; Bai et al. 2007; Hu et al. 2013; Zhang et al. 2014; Song. 2017; Tong and Chu. 2018; Hong et al. 2002). The BRs signalling-related genes including XIAO, BZR1 and TUD1 were down regulated, while BRs synthesis genes $D 2$ and $D 11$ were slightly up regulated (Fig. $8 \mathrm{~b}$ ). These results suggested that MIS2 may act as an upstream regulator in rice grain development by affecting the expression of various genes, and MIS2 probably have a complex relationship with BRs.

\section{Haplotype Analysis of MIS2 in Diverse Germplasm}

To analyze the variation of MIS2 in natural population, nucleotide polymorphism in the promoter and gene body region of MIS 2 was investigated among 524 diverse rice germplasm including japonica, indica, aus and other subspecies selected from the 3000 Rice Genomes Project (Wang et al. 2018). Excluding heterozygotes and low frequency variations, three haplotypes (Hap1, Hap2 and Hap3) were classified by single nucleotide polymorphisms (SNPs) and InDels (Fig. 9a). Interestingly, the variations in coding region were all synonymous mutations, and potential functional SNPs and InDels were only detected in promoter and untranslated regions (UTR). This indicated that the coding sequence (CDS) of MIS2 was highly conserved in cultivars and the natural mutations in CDS region may easily cause unfavorable phenotype and thus be obsoleted during breeding selection. Hap1 were represented mainly by accessions from the japonica subpopulation, containing 197 japonica, three indica and two aus cultivars. This genotype preference was also found in Hap2 and Hap3 which had high frequency in indica and aus subpopulation, respectively (Fig. 9a). Notably, compared with Hap1, an 18-bp deletion in 5'-UTR of MIS2 was detected in Hap2 and Hap3. To check the possible effect of this InDel on the MIS2 gene expression, transcript level of Hap1 and
Hap2 were examined using mRNA prepared from young panicles. The result showed that Hap1 had a bit higher expression level than Hap2 (Fig. 9b).

To investigate the phenotypic differences among the three major haplotypes, grain length, grain width, length-width ratio, 1000-grain weight and grain surface area were examined (Fig. 9c-g). The accessions carrying Hap1 displayed wider, higher 1000-grain weight and larger surface of the grain but shorter and lower lengthwidth ratio than the accessions of Hap2, whereas the Hap3 accessions were intermediate. Geographical analysis showed that Hap1 accessions which were represented by japonica varieties were mainly distributed in northern areas, whereas Hap2 and Hap3, or indica and aus accessions were mainly located in southern regions (Fig. 9h). This suggested that Hap1 may have a different origin area from Hap2 and Hap3.

\section{Discussion}

Rice is consumed as a staple food by more than half of the world's population (Huo et al. 2017; Zafar et al. 2018). Grain size and weight are the key quantitative traits affecting final grain yield in rice. Several genes that regulate grain size or shape have been identified in rice such as GS3, GS5, GSE5, GW2, SRSs and BG1 (Song et al. 2007; Tanabe et al., 2007; Abe et al., 2010; Kitagawa et al. 2010; Mao et al. 2010; Li et al., 2011; Segami et al., 2012; Duan et al. 2017). However, our understanding of the genetic mechanism of grain size development is still limited ( $\mathrm{Li}$ and Li., 2016). In this study, we report a novel grain size mutant named "mis2" which displayed smaller grains and irregular spikelet structure (Figs. 1 and 2). Cytological observations indicated that the mis2 mutant produced smaller but more epidermal cells in the lemma and palea (Fig. 2e-g), suggesting that MIS2 plays a contrasting role in regulating cell size and cell number. Interestingly, several other seed size mutants or near-isogenic lines (NILs) of rice and Arabidopsis also showed this coordinate regulation phenomenon such as gse5, NIL-TGW3, da1 and da2 (Xia et al. 2013; Duan et al. 2017; Ying et al. 2018). The mis2 mutant also produced other phenotypes such as open-hull and irregular epidermal cell wall (Figs. 1, 2). Map-based cloning identified MIS2/OsCR4 as a candidate gene for mis2 phenotype which encodes a Ser/Thr receptor-like kinase.

Several CR4 family members have been identified and characterized in different plant species including Arabidopsis, maize, and Physcomitrella patens (Becraft et al. 1996; Gifford et al. 2003; Demko et al. 2016). CR4 in maize affects leaf epidermis differentiation. $M u$ transposon insertional mutants of CR4 produced wrinkle leaves and inhibited seed aleurone formation (Becraft et al. 1996). Similar phenotypes were also found in EMS and chromosome breakage mutants (Jin et al. 2000; 


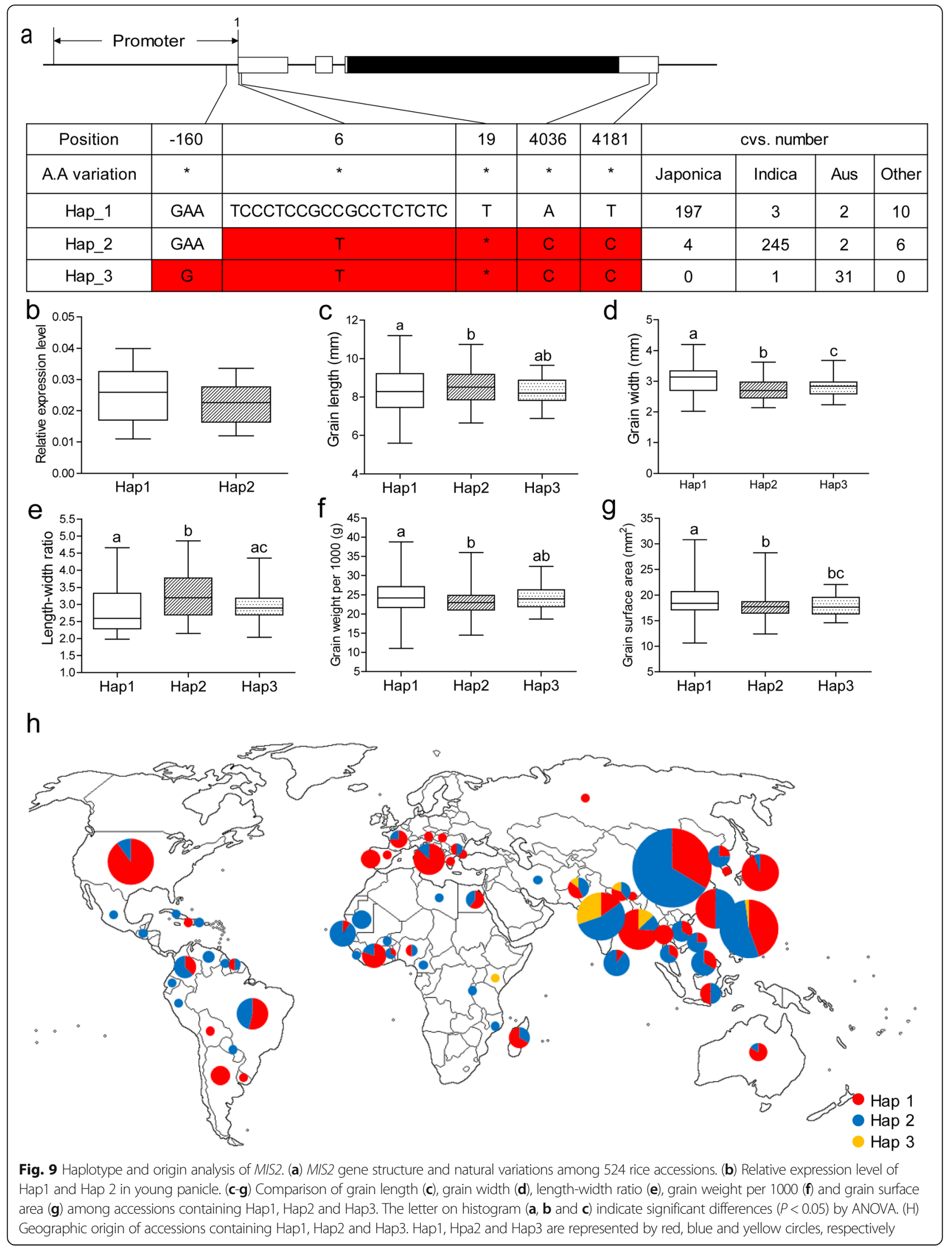


Becraft et al. 2001). The Arabidopsis acr4 mutants which contained T-DNA insertions produced abnormal epidermal cell differentiation in the seed, leaf, ovule integument, sepal margin and endothelium (Gifford et al. 2003; Watanabe et al. 2004; Cao et al. 2005). The PpCR4 deletion mutant in Physcomitrella patens generated crinkly phyllids and smaller sporophytes due to lack of differentiated margin cells and abnormal epidermal cells, respectively (Demko et al. 2016). These mutants suggest that $C R 4$ family play a vital role in epidermal cell development. Notably, OsCR4 knock-down lines created by RNA interference (RNAi) revealed the essential role of OsCR4 in maintaining the interlocking of the lemma and palea by promoting epidermal cell differentiation $(\mathrm{Pu}$ et al. 2012). However, no any loss-of-function mutant of OsCR4 have been reported in rice until now. In this study, by using a loss-of-function mutant of $O s C R 4$, we report for the first time a key role of OsCR4 in controlling grain size and shape by coordinately regulating epidermal cell size and cell number.

RLKs are characterized with an extracellular domain that serves as an important sensor molecule (Gifford et al. 2005). However, studies are required to further elucidate the mechanism of its function. Here we demonstrated that the substitution at R258Q in the sixth repeat of extracellular domain disrupted the subcellular behavior of MIS2 protein in the mis2 mutant (Fig. 7). MIS2 is mainly a plasma membrane-localized protein with some internalized vesicles. However, the R258Q mutation in MIS2 extracellular domain has changed its localization from plasma membrane to cytoplasm, suggesting a key role of extracellular domain in subcellular localization (Fig. 7). The subcellular behavior of nonfunctional MIS2 ${ }^{\mathrm{mu}}$ ::GFP was different from that of the $\mathrm{ACR} 4^{\mathrm{C} 180 \mathrm{Y}}$ :: GFP, which was localized normally to the plasma membrane (Gifford et al. 2005). Meanwhile, deleting 4.5 of seven repeats of ACR4 led to a more stable protein. Export of ACR4 protein to the membrane was normal, but the internalization was disturbed (Gifford et al. 2005). These various subcellular behaviors indicate the diversity and complexity of CR4 family protein localization and function. As plant RLKs, the fate of CR4 family protein following the internalization is still not clear. In animals, some receptor kinases such as the EGFR family have been demonstrated to undergo ubiquitination. Ubiquitination seems to play an important role in both receptor internalization and deciding whether the internalized receptor will be degraded or recycled back to the membrane (Dikic and Giordano, 2003; Marmor and Yarden, 2004). Therefore, we proposed that the substitution R258Q of MIS2 probably affect the ubiquitination signal, hence increasing the rate of internalized protein degradation and diminishing recycling back to the plasma membrane. This recycle of the protein was insufficient for the supply at plasma membrane. Additionally, it has been reported that the seven-bladed $\beta$-propeller structure mediates diverse functions especially in proteinprotein and protein-ligand interactions (Chen, et al. 2011). Whether the mutation of R258Q affect the binding between MIS2 and ligand, or break the homooligomerization or hetero-oligomerization of MIS2 with other proteins, which may influence the subsequent fate of MIS2, needs to be investigated by further studies.

HD-Zip IV transcription factors ATML1 and PDF2 play a redundant and essential role in the Arabidopsis embryo development via a universally active feedback loop (San-Bento et al. 2014; Ogawa et al. 2015). ACR4 can activate the signalling pathway of ATML1 and PDF2, resulting in dimer formation between ATML1 and PDF2. In turn, these dimers repress ACR4 and their own transcription (San-Bento et al. 2014). The atml1-3 $p d f 2-4$ double mutant displayed arrested embryos development, abnormal shoot epidermal cells and pale aborted seeds (Ogawa et al. 2015). To check whether there is a similar mechanism in rice, transcript level of $A T M L 1$ and $P D F 2$ orthologs (ROC genes) in rice were detected. Among the six $R O C$ genes, only ROC5 was significantly downregulated in the mis2 mutant (Fig. 8a), suggesting that ROC5 may act downstream of MIS2. $R O C 5$ is known to regulate leaf epidermal bulliform cells formation in rice. Knockout mutant of ROC5 produced out-curved leaves, longer panicle, more spikelets per panicle and lower seed-setting rate (Zou et al. 2011). However, there is no study on the role of ROC5 in controlling seed shape or seed epidermal cells development. This suggests that different members of the $R O C$ family could have redundant function in seed development.

To see if MIS2 regulate the expression of other seed size related genes, we measured the transcript level of several reported genes. Genes including SRS1, SRS3, SRS5, GW2, FUWA, GS5, XIAO, GSE5 and BG1 have been reported to control epidermal cell size or number in rice (Song et al. 2007; Abe et al. 2010; Li et al. 2010; Kitagawa et al. 2010; Li et al. 2011; Zou et al. 2011; Jiang et al. 2012; Segami et al. 2012; Chen et al. 2015; Liu et al. 2015; Duan et al. 2017). The expression of all these genes was significantly altered in the mis 2 mutant (Fig. 8), suggesting that MIS2 may function upstream of these genes and can affect the expression of these genes. This indicates a key role of MIS2 in regulating seed size in rice via affecting epidermal cell size or number. BRs are a class of vital phytohormones and their role in the regulation of seed size is well reported (Mori et al. 2002; Tanaka et al. 2009; Bai et al. 2007; Hu et al. 2013; Zhang et al. 2014; Song. 2017; Tong and Chu. 2018; Hong et al. 2002). To see if MIS2 participates in the BR pathway, we measured the relative expression of several BRs biosynthesis and signalling genes in WT and mis2 (Fig. 8b). 
$X I A O, B Z R 1$ and TUD1 were down-regulated in the mis2 mutant, suggesting that MIS2 may play a role in regulating seed size via affecting the BR signalling. We also observed an up-regulation in the expression of $D 2$ and D11 (two BR biosynthesis genes) which could be due to a compensatory response. Nevertheless, further confirmation studies are needed to expand our understanding about the interaction of MIS2 and BR-related genes.

Haplotype analysis revealed that the MIS2 gene was highly differentiated in various subgroups including $j a-$ ponica, indica and aus (Fig. 9a). The phenotype data of different haplotypes showed that grain width, 1000-grain weight and grain surface area of Hap1 was relatively higher than those in Hap2, while Hap2 had increased grain length and higher length-width ratio (Fig. 9c-g). Hap3 data was intermediate in these two haplotypes. Hap1, Hap2 and Hap3 accessions were mainly comprised of japonica, indica and aus respectively. Hap1 accessions were mainly distributed in northern areas, whereas Hap2 and Hap3 accessions were mainly located in southern regions, indicating that the three haplotypes may have different origins (Fig. 9h). Notably, the variations occurred in promoter and UTR regions and no missense variation in coding sequence was detected in Hap1, Hap2 and Hap3. This is probably explained by that the mutation in CDS is unfavorable for breeding. Compared with Hap1, an 18-bp fragment which contains an ERE (ethylene response elements) or GCC box was deleted from the $5^{\prime}$-UTR region of Hap2 and Hap3 (Fig. 9a). The GCC box is an 11- bp sequence (TAAGAGCCGCC) with a core GCCGCC sequence and was reported as the binding site of the AP2/EREBP (APETALA2/ethylene responsive element binding protein) family transcription factors (Ohme-Takagi and Shinshi., 1995; Büttner and Singh., 1997; Zhou et al., 1997; Fujimoto et al., 2000). In Arabidopsis and rice, AP2 family transcription factors play an important role in determining seed size and seed weight, such as APETALA2, RSR1 and SSH1 (Ohto et al., 2005; Jofuku et al., 2005; Fu and Xue, 2010; Jiang et al. 2019b). Therefore, we hypothesize that this deletion probably abolishes the binding of certain AP2 family transcription factor to the 5'UTR region of MIS2, leading to different expression level in various haplotypes (Fig. 9b).

\section{Conclusions}

In this study, a rice mini seed 2 (mis2) mutant was characterized. The smaller grain was due to the coordinate alternation in epidermal cell size and cell number, while the wrinkle surface was due to the irregular shape and variable size of epidermal cells. The MIS2 gene was revealed to encode the receptor-like kinase CRINKLY4 (CR4) known to regulate epidermal cell differentiation. The MIS2 protein is localized primarily on the plasma membrane along with the endosome. The mis 2 mutant protein harboring the Arg258Gln substitution in extracellular domain disturbed its localization on the plasma membrane probably due to insufficient recycling of CR4 from endosome to plasma membrane. Haplotype analysis of MIS2 in 524 diverse rice accessions revealed an 18-bp INDEL in the $5^{\prime}$-UTR region but no missense mutation in the coding region. This study suggests that CR4 is essential for the rice grain development and the extracellular domain is required for its proper subcellular localization and function.

\section{Supplementary information}

Supplementary information accompanies this paper at https://doi.org/10. 1186/s12284-020-0368-9.

Additional file 1 Figure S1. Phenotype of the mi2 mutant plant. Figure S2. Sequence alignments of CR4 family protein from rice, maize and Arabidopsis. Figure S3. Phylogenetic analysis of CR4 family and CR4related proteins. Table $\mathbf{S 1}$. Primers used in this study.

\section{Abbreviations}

CDS: Coding sequence; CR4: CRINKLY4; EMS: Ethyl methane sulphonate; INDEL: Insertion and deletion; mis2: Mini seed 2; ORF: Open reading frame; RLK: Receptor-like kinase; SEM: Scanning electron microscopy (SEM); SNP: Single nucleotide polymorphisms; TEM: Transmission electron microscopy; TNFR: Tumor necrosis factor receptor-like; UTR: Untranslated region

\section{Acknowledgements}

We thank Prof. Zhikang Li and Jianlong Xu (Institute of Crop Science, Chinese Academy of Agricultural Sciences) for providing the 524 rice accessions, Prof. Hang He (Peking University) for haplotype analysis, Prof. Dali Zeng (China National Rice Research Institute) for providing field to grow transgenic plants.

\section{Authors' Contributions}

X.L. and Y.C. designed the project. Y.C., J.F., J.S., J.Z., S.Y. performed the experiments. X.L. and Y.C. analyzed the data. Y.C. S.A.Z. and X.L. wrote the manuscript. All authors had read and approved the manuscript.

\section{Funding}

This research was supported by National Major Project for Developing New GM Crops (2016ZX08009-003), and the National Key R\&D Program of China (2016YFD0100401) and the Agricultural Science and Technology Innovation Program of Chinese Academy of Agricultural Sciences.

\section{Availability of Data and Materials}

The authors declare that all data generated or analyzed during this study are available within the manuscript or its supplementary files or are available from the corresponding authors upon request.

Ethics Approval and Consent to Participate No applicable.

Consent for Publication

No applicable.

\section{Competing Interests}

The authors declare that they have no competing interests.

\section{Author details}

${ }^{1}$ National Key Facility for Crop Gene Resources and Genetic Improvement, Institute of Crop Science, Chinese Academy of Agricultural Sciences, Beijing 100081, China. ${ }^{2}$ Shandong Rice Research Institute, Jinan 250100, China. 
Received: 19 September 2019 Accepted: 20 January 2020

\section{Published online: 31 January 2020}

\section{References}

Abe M, Katsumata H, Komeda Y, Takahashi T (2003) Regulation of shoot epidermal cell differentiation by a pair of homeodomain proteins in Arabidopsis. Dev 130:635-643

Abe Y, Mieda K, Ando T, Kono I, Yano M, Kitano H, Iwasaki Y (2010) The SMALL AND ROUND SEED1 (SRS1/DEP2) gene is involved in the regulation of seed size in rice. Genes Genet Syst 85:327-339

Ahmadi N, Audebert A, Bennett MJ, Bishopp A, de Oliveira AC, Courtois B, Diedhiou A, Diévart A, Gantet P, Ghesquière A, Guiderdoni E, Henry A, Inukai Y, Kochian L, Laplaze L, Lucas M, Luu DT, Manneh B, Mo X, Muthurajan R, Périn C, Price A, Robin S, Sentenac H, Sine B, Uga Y, Véry AA, Wissuwa M, Wu P, Xu J (2014) The roots of future rice harvests. Rice 7:29

Arnold K, Bordoli L, Kopp J, Schwede T (2006) The SWISS-MODEL workspace: a web-based environment for protein structure homology modelling. Bioinform 22:195-201

Bai MY, Zhang LY, Gampala SS, Zhu SW, Song WY, Chong K, Wang ZY (2007) Functions of OsBZR1 and 14-3-3 proteins in brassinosteroid signaling in rice. Proc Natl Acad Sci U S A 104:13839-13844

Becraft P, Stinard P, McCarty D (1996) CRINKLY4: a TNFR-like receptor kinase involved in maize epidermal differentiation. Sci 273:1406-1409

Becraft PW, Kang SH, Suh SG (2001) The maize CRINKLY4 receptor kinase controls a cell-autonomous differentiation response. Plant Physiol 127:486-496

Benkert P, Biasini M, Schwede T (2011) Toward the estimation of the absolute quality of individual protein structure models. Bioinform 27:343-350

Biasini M, Bienert S, Waterhouse A, Arnold K, Studer G, Schmidt T, Kiefer F, Gallo Cassarino T, Bertoni M, Bordoli L, Schwede T (2014) SWISS-MODEL: modelling protein tertiary and quaternary structure using evolutionary information. Nucleic Acids Res 42:W252-W258

Büttner M, Singh KB (1997) Arabidopsis thaliana ethylene-responsive element binding protein (AtEBP), an ethylene-inducible, GCC box DNA-binding protein interacts with an ocs element binding protein. Proc Natl Acad Sci U S A 94:5961-5966

Cao X, Li K, Suh S, Guo T, Becraft (2005) Molecular analysis of the CRINKLY4 gene family in Arabidopsis thaliana. Planta 220:645-657

Chen CK, Chan NL, Wang AH (2011) The many blades of the $\beta$-propeller proteins: conserved but versatile. Trends Biochem Sci 36:553-561

Chen J, Gao H, Zheng XM, Jin M, Weng JF, Ma J, Ren Y, Zhou K, Wang Q, Wang J, Wang JL, Zhang X, Cheng Z, Wu C, Wang H, Wan JM (2015) An evolutionarily conserved gene, FUWA, plays a role in determining panicle architecture, grain shape and grain weight in rice. Plant J 83:427-438

Cock JM, Vanoosthuyse V, Gaude T (2002) Receptor kinase signalling in plants and animals: distinct molecular systems with mechanistic similarities. Curr Opin Cell Biol 14:230-236

Demko V, Ako E, Perroud PF, Quatrano R, Olsen OA (2016) The phenotype of the CRINKLY4 deletion mutant of Physcomitrella patens suggests a broad role in developmental regulation in early land plants. Planta 244:1-10

Dikic I, Giordano S (2003) Negative receptor signalling. Curr Opin Cell Biol 15:128-135

Duan P, Xu J, Zeng D, Zhang B, Geng M, Zhang G, Huang K, Huang L, Xu R, Ge S, Qian Q, Li Y (2017) Natural variation in the promoter of GSE5 contributes to grain size diversity in rice. Mol Plant 10:685-694

Ebine K, Fujimoto M, Okatani Y, Nishiyama T, Goh T, Ito E, Dainobu T, Nishitani A, Uemura T, Sato MH, Thordal-Christensen H, Tsutsumi N, Nakano A, Ueda T (2011) A membrane trafficking pathway regulated by the plant-specific RAB GTPase ARA6. Nat Cell Biol 13:853-859

Fu FF, Xue HW (2010) Coexpression analysis identifies rice starch regulator1, a rice AP2/EREBP family transcription factor, as a novel rice starch biosynthesis regulator. Plant Physiol 154:927-938

Fujimoto SY, Ohta M, Usui A, Shinshi H, Ohme-Takagi M (2000) Arabidopsis ethylene-responsive element binding factors act as transcriptional activators or repressors of GCC box-mediated gene expression. Plant Cell 12:393-404

Gifford ML, Dean S, Ingram GC (2003) The Arabidopsis ACR4 gene plays a role in cell layer organisation during ovule integument and sepal margin development. Dev 130:4249-4258

Gifford ML, Robertson FC, Soares DC, Ingram GC (2005) ARABIDOPSIS CRINKLY4 function, internalization, and turnover are dependent on the extracellular CRINKLY repeat domain. Plant Cell 17:1154-1166

Guo T, Chen K, Dong NQ, Shi CL, Ye WW, Gao JP, Shan JX, Lin HX (2018) GRAIN SIZE AND NUMBER1 negatively regulates the OsMKKK10-OsMKK4-OsMPK6 cascade to coordinate the trade-off between grain NUMBER per panicle and grain size in rice. Plant Cell 30:871-888

Hong Z, Ueguchi-Tanaka M, Shimizu-Sato S, Inukai Y, Fujioka S, Shimada Y, Takatsuto S, Agetsuma M, Yoshida S, Watanabe Y, Uozu S, Kitano H, Ashikari M, Matsuoka M (2002) Loss-of-function of a rice brassinosteroid biosynthetic enzyme, C-6 oxidase, prevents the organized arrangement and polar elongation of cells in the leaves and stem. Plant J 32:495-508

Hu X, Qian Q, Xu T, Zhang Y, Dong G, Gao T, Xie Q, Xue Y (2013) The U-box E3 ubiquitin ligase TUD1 functions with a heterotrimeric $G$ a subunit to regulate Brassinosteroid-mediated growth in rice. PLoS Genet 9:e1003391

Huang R, Jiang L, Zheng J, Wang T, Wang H, Huang Y, Hong Z (2013) Genetic bases of rice grain shape: so many genes, so little known. Trends Plant Sci 18:218-226

Huo X, Wu S, Zhu Z, Liu F, Fu Y, Cai H, Sun X, Gu P, Xie D, Tan L, Sun C (2017) NOG1 increases grain production in rice. Nat Commun 8:1497

Jefferson RA, Kavanagh TA, Bevan MW (1987) GUS fusions: beta-glucuronidase as a sensitive and versatile gene fusion marker in higher plants. EMBO I 6:3901-3907

Jiang L, Li G, Chern M, Jian R, Pham NT, Martin JA, Schackwitz WS, Zhao J, Ruan D, Huang R, Zheng J, Ronald PC (2019a) Whole-genome sequencing identifies a rice grain shape mutant, gs9-1. Rice 12:52

Jiang L, Ma X, Zhao S, Tang Y, Liu F, Gu P, Fu Y, Zhu Z, Cai H, Sun C, Tan L (2019b) The APETALA2-like transcription factor SUPERNUMERARY BRACT controls rice seed shattering and seed size. Plant Cell 31:17-36

Jiang Y, Bao L, Jeong SY, Kim SK, XU C, Li X, Zhang Q (2012) XIAO is involved in the control of organ size by contributing to the regulation of signaling and homeostasis of brassinosteroids and cell cycling in rice. Plant J 70:398-408

Jin P, Guo T, Becraft PW (2000) The maize CR4 receptor-like kinase mediates a growth factor-like differentiation response. Genesis 27:104-116

Jofuku KD, Omidyar PK, Gee Z, Okamuro JK (2005) Control of seed mass and seed yield by the floral homeotic gene APETALA2. Proc Natl Acad Sci U S A 102:3117-3122

Kitagawa K, Kurinami S, Oki K, Abe Y, Ando T, Kono I, Yano M, Kitano H, Iwasaki Y (2010) A novel kinesin 13 protein regulating rice seed length. Plant Cell Physiol 51:1315-1329

Kumar S, Stecher G, Li M, Knyaz C, Tamura K (2018) MEGA X: molecular evolutionary genetics analysis across computing platforms. Mol Biol Evol 35:1547-1549

Li F, Liu W, Tang J, Chen J, Tong H, Hu B, Li C, Fang J, Chen M, Chu C (2010) Rice DENSE AND ERECT PANICLE 2 is essential for determining panicle outgrowth and elongation. Cell Res 20:838-849

Li N, Li Y (2016) Signaling pathways of seed size control in plants. Curr Opin Plant Biol 33:23-32

Li Y, Fan C, Xing Y, Jiang Y, Luo L, Sun L, Shao D, Xu C, Li X, Xiao J, He Y, Zhang $Q$ (2011) Natural variation in GS5 plays an important role in regulating grain size and yield in rice. Nat Genet 43:1266-1269

Liu L, Tong H, Xiao Y, Che R, Xu F, Hu B, Liang C, Chu J, Li J, Chu C (2015) Activation of Big Grain1 significantly improves grain size by regulating auxin transport in rice. Proc Natl Acad Sci U S A 112:11102-11107

Mao H, Sun S, Yao J, Wang C, Yu S, Xu C, Li X, Zhang Q (2010) Linking differential domain functions of the GS3 protein to natural variation of grain size in rice. Proc Natl Acad Sci U S A 107:19579-19584

Marmor MD, Yarden Y (2004) Role of protein ubiquitylation in regulating endocytosis of receptor tyrosine kinases. Oncogene 23:2057-2070

Mori M, Nomura T, Ooka H, Ishizaka M, Yokota T, Sugimoto K, Okabe K, Kajiwara H, Satoh K, Yamamoto K, Hirochika H, Kikuchi S (2002) Isolation and characterization of a rice $d$ warf mutant with a defect in brassinosteroid biosynthesis. Plant Physiol 130:1152-1161

Nan J, Feng X, Wang C, Zhang X, Wang R, Liu J, Yuan Q, Jiang G, Lin S (2018) Improving rice grain length through updating the GS3 locus of an elite variety Kongyu 131. Rice 11:21

Ogawa E, Yamada Y, Sezaki N, Kosaka S, Kondo H, Kamata N, Abe M, Komeda Y, Takahashi T. (2015) ATML1 and PDF2 play a redundant and essential role in Arabidopsis embryo development. Plant Cell Physiol 56:1183-1192

Ohme-Takagi M, Shinshi H (1995) Ethylene-inducible DNA binding proteins that interact with an ethylene-responsive element. Plant Cell 7:173-182

Ohto MA, Fischer RL, Goldberg RB, Nakamura K, Harada JJ (2005) Control of seed mass by APETALA2. Proc Natl Acad Sci U S A 102:3123-3128

Pu C, Ma Y, Wang J, Zhang Y, Jiao X, Hu Y, Wang L, Zhu Z, Sun D, Sun Y (2012) Crinkly 4 receptor-like kinase is required to maintain the interlocking of the palea and lemma, and fertility in rice, by promoting epidermal cell differentiation. Plant J 70:940-953

Pu CX, Han YF, Zhu S, Song FY, Zhao Y, Wang CY, Zhang YC, Yang Q, Wang J, Bu SL, Sun LJ, Zhang SW, Zhang SQ, Sun DY, Sun Y (2017) The rice receptor-like 
kinases DWARF AND RUNTISH SPIKELET1 and 2 repress cell death and affect sugar utilization during reproductive development. Plant Cell 29:70-89

Qin Y, Yang L, Sun Z, Wang X, Wang Y, Zhang J, Rehman AU, Chen Z, Qi J, Wang B, Song CP, Yang S, Gong Z (2019) Redox-mediated endocytosis of a receptor-like kinase during distal stem cell differentiation depends on its tumor necrosis factor receptor domain. Plant Physiol doi. https:/doi.org/10.1104/pp.19.00616

San-Bento R, Farcot E, Galletti R, Creff A, Ingram G (2014) Epidermal identity is maintained by cell-cell communication via a universally active feedback loop in Arabidopsis thaliana. Plant J 77:46-58

Segami S, Kono I, Ando T, Yano M, Kitano H, Miura K, Iwasaki Y (2012) Small and round seed 5 gene encodes alpha-tubulin regulating seed cell elongation in rice. Rice 5:4

Si L, Chen J, Huang X, Gong H, Luo J, Hou Q, Zhou T, Lu T, Zhu J, Shangguan Y, Chen E, Gong C, Zhao Q, Jing Y, Zhao Y, Li Y, Cui L, Fan D, Lu Y, Weng Q, Wang Y, Zhan Q, Liu K, Wei X, An K, An G, Han B (2015) OsSPL13 controls grain size in cultivated rice. Nat Genet 48:447-456

Song XJ (2017) Crop seed size: BR matters. Mol Plant 10:668-669

Song XJ, Huang W, Shi M, Zhu MZ, Lin HX (2007) A QTL for rice grain width and weight encodes a previously unknown RING-type E3 ubiquitin ligase. Nat Genet 39:623-630

Tan YF, Xing YZ, Li JX, Yu SB, Xu CG, Zhang QF (2000) Genetic bases of appearance quality of rice grains in shanyou 63 , an elite rice hybrid. Theor Appl Genet 101:823-829

Tanabe S, Mieda K, Ashikari M, Kitano H, Iwasaki Y (2007) Mapping of Small and Round Seed 1 gene in rice. Rice Genet Newsletters 23:44-47

Tanaka A, Nakagawa H, Tomita C, Shimatani Z, Ohtake M, Nomura T, Jiang CJ, Dubouzet JG, Kikuchi S, Sekimoto H, Yokota T, Asami T, Kamakura T, Mori M (2009) BRASSINOSTEROID UPREGULATED1, encoding a helix-loop-helix protein, is a novel gene involved in brassinosteroid signaling and controls bending of the lamina joint in rice. Plant Physiol 151:669-680

Tanaka H, Watanabe M, Sasabe M, Hiroe T, Tanaka T, Tsukaya H, Ikezaki M, Machida C, Machida Y (2007) Novel receptor-like kinase ALE2 controls shoot development by specifying epidermis in Arabidopsis. Dev 134:1643-1652

Tanaka H, Watanabe M, Watanabe D, Tanaka T, Machida C, Machida Y (2002) ACR4, a putative receptor kinase gene of Arabidopsis thaliana, that is expressed in the outer cell layers of embryos and plants, is involved in proper embryogenesis. Plant and Cell Physiol 43:419-428

Tian Q, Olsen L, Sun B, Lid S, Brown R, Lemmon B, Fosnes K, Gruis D, OpsahlSorteberg H, Otegui M, Olsen O (2007) Subcellular localization and functional domain studies of DEFECTIVE KERNEL1 in maize and Arabidopsis suggest a model for aleurone cell fate specification involving CRINKLY4 and SUPERNUMERARY ALEURONE LAYER1. Plant Cell 19:3127-3145

Tichtinsky G, Vanoosthuyse V, Cock JM, Gaude T (2003) Making inroads into plant receptor kinase signalling pathways. Trends Plant Sci 8:231-237

Tong H, Chu C (2018) Functional specificities of brassinosteroid and potential utilization for crop improvement. Trends Plant Sci 23:1016-1028

Tsutsui T, Nakano A, Ueda T (2015) The plant-specific RAB5 GTPase ARA6 is required for starch and sugar homeostasis in Arabidopsis thaliana. Plant Cell Physiol 56:1073-1083

Ueda T, Yamaguchi M, Uchimiya H, Nakano A (2001) Ara6, a plant-unique novel type Rab GTPase, functions in the endocytic pathway of Arabidopsis thaliana. The EMBO I 20:4730-4741

Wang E, Wang J, Zhu X, Hao W, Wang L, Li Q, Zhang L, He W, Lu B, Lin H, Ma H, Zhang G, He Z (2008) Control of rice grain-filling and yield by a gene with a potential signature of domestication. Nat Genet 40:1370-1374

Wang S, Li S, Liu Q, Wu K, Zhang J, Wang S, Wang Y, Chen X, Zhang Y, Gao C, Wang F, Huang H, Fu X (2015b) The OsSPL16-GW7 regulatory module determines grain shape and simultaneously improves rice yield and grain quality. Nat Genet 47:949-954

Wang W, Mauleon R, Hu Z, Chebotarov D, Tai S, Wu Z, Li M, Zheng T, Fuentes RR, Zhang F, Mansueto L, Copetti D, Sanciangco M, Palis KC, Xu J, Sun C, Fu B, Zhang H, Gao Y, Zhao X, Shen F, Cui X, Yu H, Li Z, Chen M, Detras J, Zhou Y, Zhang X, Zhao Y, Kudrna D, Wang C, Li R, Jia B, Lu J, He X, Dong Z, Xu J, Li Y, Wang M, Shi J, Li J, Zhang D, Lee S, Hu W, Poliakov A, Dubchak I, Ulat VJ, Borja FN, Mendoza JR, Ali J, Li J, Gao Q, Niu Y, Yue Z, Naredo MEB, Talag J, Wang X, Li $J$, Fang $X$, Yin Y, Glaszmann JC, Zhang J, Li J, Hamilton RS, Wing RA, Ruan J, Zhang G, Wei C, Alexandrov N, McNally KL, Li Z, Leung H (2018) Genomic variation in 3,010 diverse accessions of Asian cultivated rice. Nature 557:43-49

Wang Y, Xiong G, Hu J, Jiang L, Yu H, Xu J, Fang Y, Zeng L, Xu E, Xu J, Ye W, Meng X, Liu R, Chen H, Jing Y, Wang Y, Zhu X, Li J, Qian Q (2015a) Copy number variation at the GL7 locus contributes to grain size diversity in rice. Nat Genet 47:944-948
Watanabe M, Tanaka H, Watanabe D, Machida C, Machida Y (2004) The ACR4 receptor-like kinase is required for surface formation of epidermis-related tissues in Arabidopsis thaliana. Plant J 39:298-308

Xia T, Li N, Dumenil J, Li J, Kamenski A, Bevan MW, Gao F, Li Y (2013) The ubiquitin receptor DA1 interacts with the E3 ubiquitin ligase DA2 to regulate seed and organ size in Arabidopsis. Plant Cell 25:3347-3359

Xu R, Duan P, Yu H, Zhou Z, Zhang B, Wang R, Li J, Zhang G, Zhuang S, Lyu J, Li N Chai T, Tian Z, Yao S, Li Y (2018a) Control of grain size and weight by the OsMKKK10-OsMKK4-OsMAPK6 signaling pathway in Rice. Mol Plant 11:860-873

Xu R, Yu H, Wang J, Duan P, Zhang B, Li J, Li Y, Xu J, Lyu J, Li N, Chai T, Li Y (2018b) A mitogen-activated protein kinase phosphatase influences grain size and weight in rice. Plant J 95:937-946

Ying JZ, Ma M, Bai C, Huang XH, Liu JL, Fan YY, Song XJ (2018) TGW3, a major QTL that negatively modulates grain length and weight in rice. Mol Plant 11:750-753

Zafar SA, Hameed A, Nawaz MA, Wei M, Noor MA, Hussain M, Rehman M (2018) Mechanisms and molecular approaches for heat tolerance in rice (Oryza sativa L.) under climate change scenario. J INTEGR AGR 17(4):726-738

Zafar SA, Patil SB, Uzair M, Fang J, Zhao J, Yuan S, Uzair M, Luo Q, Shi J, Schreiber L, Li X (2020) DEGENERATED PANICLE AND PARTIAL STERILITY 1 (DPS1) encodes a CBS domain containing protein required for anther cuticle and panicle development in rice. New Phytol 225:356-375

Zeng X, Ren Z, Wu Q, Fan J, Peng PP, Tang K, Zhang R, Zhao KH, Yang X (2015) Dynamic crystallography reveals early signalling events in ultraviolet photoreceptor UVR8. Nat Plants. https://doi.org/10.1038/nplants

Zhang C, Bai MY, Chong K (2014) Brassinosteroid-mediated regulation of agronomic traits in rice. Plant Cell Rep 33:683-696

Zhou J, Tang X, Martin GB (1997) The Pto kinase conferring resistance to tomato bacterial speck disease interacts with proteins that bind a cis-element of pathogenesis-related genes. The EMBO J 16:3207-3218

Zou L, Sun X, Zhang Z, Liu P, Wu J, Tian C, Qiu J, Lu T (2011) Leaf rolling controlled by the homeodomain leucine zipper class IV gene Roc5 in rice. Plant Physiol 156(3):1589-1602

\section{Publisher's Note}

Springer Nature remains neutral with regard to jurisdictional claims in published maps and institutional affiliations.

\section{Submit your manuscript to a SpringerOpen ${ }^{\circ}$ journal and benefit from:}

- Convenient online submission

- Rigorous peer review

- Open access: articles freely available online

- High visibility within the field

- Retaining the copyright to your article

Submit your next manuscript at $\boldsymbol{\nabla}$ springeropen.com 